\title{
Efectos económicos de reformas impositivas alternativas para el combate a la pobreza en México para el año 2012
}

\author{
BELTRÁN JAIMES, LUZ DARY \\ Departamento de Gestión de la Tecnología e Innovación \\ Instituto Politécnico Nacional \\ Correo electrónico: lbeltranj@ipn.mx \\ Cardenete Flores, Manuel Alejandro \\ Departamento de Economía \\ Universidad Loyola \\ Correo electrónico: macardenete@uloyola.es \\ Delgado López, MARÍA del CARMEN \\ Departamento de Economía \\ Universidad Loyola \\ Correo electrónico: mcdelgado@uloyola.es
}

\begin{abstract}
RESUMEN
Esta investigación analiza el impacto económico de tres reformas impositivas alternativas sobre la economía mexicana y sobre los índices de pobreza y de desigualdad, que reforzarían el programa actual para el combate a la pobreza en el país. Como principal resultado se tiene que para generar un mayor impacto económico y reducir los índices de pobreza en mayor proporción, se deberá incrementar los fondos del programa Oportunidades financiado a través de un aumento del $5 \%$ al ISR, para transferirlo a los tres primeros deciles, cuidando su adecuada focalización, aunado a transferencias directas a la salud y educación.
\end{abstract}

Palabras clave: modelo multisectorial, matriz de contabilidad social, pobreza, desigualdad.

Clasificación JEL: C67; H53; I32; I38.

MSC2010: 00A69; 62P20; 91B66.

Artículo recibido el 21 de junio de 2018 y aceptado el 12 de febrero de 2019 


\title{
Economic effects of alternative tax reforms for the fight against poverty in Mexico for 2012
}

\begin{abstract}
This research analyzes the economic impact of three alternative tax reforms on the Mexican economy, poverty and inequality, to strengthen the current program to fight against poverty in the country. The main result must be to generate greater economic impact and reduce poverty in greater proportion, should increase Oportunidades program funds financed through an increase of 5\% to ISR and transferred to the first three deciles caring proper targeting, coupled with direct health and education transfers.
\end{abstract}

Keywords: multisectoral model; social accounting matrix; poverty; inequality.

JEL classification: C67; H53; I32; I38.

MSC2010: 00A69; 62P20; 91B66.

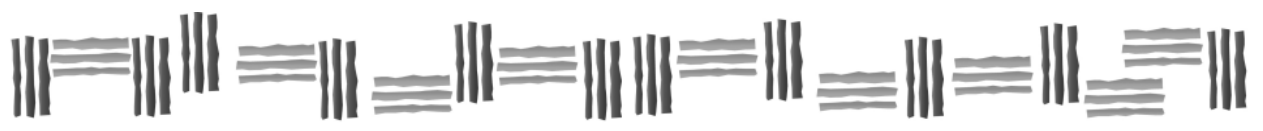




\section{Introducción.}

Como producto de la preocupación mundial acerca de la desigualdad y pobreza, han sido propuestos como parte de la política social de los países en vías de desarrollo diferentes programas para su combate. Algunos de ellos son los programas de Transferencias Monetarias Condicionadas (TMC), cuyo objetivo es romper el ciclo intergeneracional de la pobreza por medio de la inversión en capital humano con la que debería ser posible que la siguiente generación salga de la pobreza. Asimismo, estos programas afectan tanto el ingreso como el consumo de las familias, además de los servicios sociales, el nivel educativo y la salud y nutrición de la población receptora de esas transferencias.

Con el fin de mejorar los efectos de dichos programas sobre la población vulnerable, han surgido diferentes enfoques para su diseño y evaluación. Uno de estos es el enfoque de manejo de riesgos, que busca desarrollar capital humano como herramienta para generar capacidades y combatir la pobreza en el largo plazo. De acuerdo a Holzmann y Jorgensen (2000), el enfoque de riesgos sociales se centra en los pobres, ya que son los más vulnerables a los riesgos, pues carecen de instrumentos adecuados con los que podrían superar y eliminar dichos riesgos, impidiéndoles involucrarse en actividades con más riesgo, pero más rentables que les permitan salir de dicha pobreza.

Los programas de TMC buscan generar capital humano, principalmente a través del fomento a la educación, salud y alimentación. Según Skoufias y Parker (2001), este tipo de programas resultan ser una buena vía para el combate a la pobreza, ya que reducen el costo de oportunidad de la escolarización y refuerzan el efecto ingreso de la transferencia, pues tanto el trabajo infantil como la escolaridad son sustitutos. A corto plazo busca reducir la pobreza mediante las transferencias de ingreso. A largo plazo busca fortalecer las capacidades humanas a través del acceso a servicios de salud y educación, o a través del mejoramiento de unos mínimos sociales, por lo que, al momento de evaluarla, se esperan diferentes efectos en estas dimensiones (Cecchini \& Martínez, 2011).

Para el caso de México, el programa más importante del gobierno desde hace más de una década ha estado en funcionamiento bajo el nombre de Oportunidades ${ }^{1}$ cuyo objetivo es favorecer el desarrollo de las capacidades asociadas a la educación, salud y nutrición de las familias beneficiarias, para contribuir a la ruptura del ciclo intergeneracional de la pobreza.

No obstante, los programas de transferencias condicionadas presentan algunas limitaciones; Britto (2005) menciona que es subjetivo que las transferencias destinadas a la educación se transformen en el largo plazo en mayores ingresos monetarios, ya que depende de otras variables como la oferta educativa, su calidad, el desempleo, los salarios percibidos, etc. Además, estos programas deben incluir medidas para el medio plazo que fomenten la inclusión laboral y la generación autónoma de ingresos de los adultos en edad de trabajar. Así, como considerar la calidad de la salud y educación indicadores finales de capital humano.

De acuerdo con Cecchini y Madariaga (2011), las repercusiones de las transferencias en los indicadores de pobreza a nivel nacional se manifiestan en el índice de brecha de pobreza (FGT $(\alpha=1))$ y severidad de la pobreza $((\alpha=2))$ ya que las transferencias suelen focalizarse en los más pobres. Sin embargo, no siempre representan un monto elevado, de manera que logran acercarlos

\footnotetext{
${ }^{1}$ Fue creado en 1997 bajo el nombre de Progresa con una cobertura de 300.000 familias y solo operaba en el ámbito rural; a mediados del 2002 este programa cambió de nombre a Oportunidades ampliando su cobertura y expandiendo las becas a educación media superior. En el 2014 este programa cambia nuevamente de nombre a Prospera incluyendo acciones relacionadas con el fomento productivo, generación de ingresos, bienestar económico, inclusión financiera y laboral, educación, alimentación y salud. Para el caso de esta investigación, se analiza bajo el nombre de Oportunidades ya que es la que cuenta con mayor información hasta el momento (Prospera, 2015).
} 
a la línea de la pobreza, pero no necesariamente superarla. Por otro lado, afirman que Oportunidades presenta resultados importantes en cuanto a la distribución del ingreso (una reducción de la desigualdad de alrededor de 2,7 puntos). Asimismo, afirma que busca efectos de largo plazo ${ }^{2}$, y no solo en un momento dado.

Yaschine y Dávila (2008) exponen que, estos programas por sí solos no permiten superar la pobreza. Para el caso de México, más concretamente del programa Oportunidades, pasados tres años del programa, solo el $2 \%$ del total de las familias alcanzan los umbrales de egreso del sistema y después de seis años el $20 \%$. De estos, el $42 \%$ de los egresados del programa vuelve a vivir en condiciones de pobreza.

Por otro lado, Villatoro (2005) encuentra que los programas de TMC logran, en algunos casos, reducir la brecha de la pobreza, y en otros, mitigar las consecuencias de una crisis económica. Pero, no queda claro su capacidad de lograr que los beneficiarios superen la línea de la pobreza; ésta depende del monto de la transferencia, de la focalización y de la ausencia de contracciones económicas. En el largo plazo, la superación de la pobreza depende de la capacidad de generación de ingreso de los hogares, pero, a su vez depende de la calidad del aprendizaje adquirido en el periodo previo y las tasas de desempleo. Por lo que se debería tener en cuenta el mejoramiento de la educación y los programas de inserción laboral. Sin embargo, Gertler, Martínez y Rubio (2012) encontraron que los hogares beneficiados después de 6 años de permanencia en el programa incrementan su ingreso en un $22 \%$.

No obstante, la focalización es un tema principal en este tipo de programas y Oportunidades no es la excepción. De acuerdo con Escobar-Latopí, González de la Rocha y Cortés (2005), el programa ha presentado problemas de focalización, ya que la mayoría de los hogares que están logrando salir del programa por haber superado la línea de la pobreza, no debieron haber estado beneficiados. Asimismo, Campos-Vazquez, Esquivel y Lustig (2014) concluyen que, en zonas rurales muy marginadas, las familias beneficiarias no tienen oportunidad de dejar de ser beneficiarios (superar el umbral de pobreza) debido a la falta de consideración del contexto o mercado laboral de la zona en las que se encuentra la familia.

Este artículo tiene como objeto buscar alguna otra alternativa redistributiva que complemente el programa Oportunidades a través de diferentes políticas impositivas orientadas a lograr una mejor distribución de la renta, cuyos efectos se vean reflejados en los índices de pobreza y coeficiente de Gini. Aunque, el programa Oportunidades presenta un importante problema de focalización y un background de corrupción en este punto, este tema se sale del alcance de la investigación. En consecuencia, la propuesta tiene como objetivo definir alternativas que reemplacen o complementen dicho programa ${ }^{3}$ debido a la permanencia de los niveles de pobreza, e identificar el efecto generado entre los agentes económicos y el output total de la economía. Finalmente, a partir de estos identificar su impacto en la desigualdad y en los índices de pobreza. Para cada una de ellas, se utiliza un modelo lineal de equilibrio general (MLEG) como metodología de análisis.

Se proponen tres escenarios alternativos para el combate a la pobreza, partiendo de la necesidad de financiarlos a través de reformas impositivas. Estos son: un aumento del Impuesto al valor agregado (IVA) del 2\%, un aumento del Impuesto Sobre la Renta (ISR) del 5\% y la

\footnotetext{
${ }^{2}$ La visión del programa Oportunidades es erradicar la pobreza para el año 2030, a través de la ruptura del ciclo intergeneracional de pobreza, reflejado en la reducción de las cifras.

${ }^{3}$ La población con un ingreso inferior a la línea de bienestar mínimo en México para el periodo 2008-2012 pasó del 16,7\% a 19,4\%, siendo esta diferencia estadísticamente significativa, es decir, se incrementó en 3,4 millones de habitantes. De la misma manera, el número de población con un ingreso inferior a la línea de bienestar para el mismo periodo aumentó de $49 \%$ a $52 \%$ siendo esta diferencia estadísticamente significativa, con un aumento de 4,8 millones de habitantes.
} 
recaudación de los impuestos evadidos por uso de efectivo (IEUE). Con cada uno de ellos se realiza una simulación del impacto de la propuesta en el total de la economía, seguido de un análisis de su impacto en los índices de pobreza y en el coeficiente de Gini. Finalmente se realiza una comparación entre ellos en busca de seleccionar la simulación que arroje mejores resultados.

Cabe resaltar que, aunque el IVA y el ISR son considerados complementarios, ya que el IVA puede actuar como instrumentos de control de los causantes del ISR (Tello \& Hernández, 2010), en esta investigación, como ya se señaló, se tomará como medida complementaria del programa Oportunidades, solo una de las dos propuestas: la que arroje mejores resultados en cuanto a la distribución de los ingresos. México por muchos años se ha caracterizado por ser uno de los países a nivel mundial con menor recaudación de impuestos, debido principalmente a la evasión de impuestos y a la informalidad creciente, aunado a una mala administración tributaria. Sin embargo, como menciona Casares et al. (2015), en países con gasto público ineficiente y altos grados de corrupción, es difícil realizar reformas impositivas, por lo que, resulta relevante simular los efectos de la recaudación del IEUE, que acompañe a cualquiera de las dos reformas impositivas propuestas, con el fin de suponer una mejora en la eficiencia recaudatoria.

En cuanto a recaudación de impuestos, México se ha caracterizado por tener uno de los sistemas impositivos con menor carga tributaria de América Latina. De acuerdo con Minzer, Pérez y Solís (2014) en el 2008, México ocupó el último lugar de los países latinoamericanos con unos ingresos tributarios del 8,2\% del PIB, siendo el 5,3\% del PIB recolectado por imposiciones directas (ISR), el 2,7\% del PIB por imposiciones indirectas (IVA) y el 0,2\% del PIB por otro tipo de imposiciones. México ha estado estancado prácticamente desde 1970 hasta la fecha. En este periodo, sobresalen la reforma realizada en 1980 con la inclusión del IVA, impuesto que, a la fecha, solo ha sido modificado de acuerdo con las misceláneas fiscales propuestas en cada gobierno. Situación similar con el ISR; entre las modificaciones realizadas destacan la inclusión de las ganancias de capital en la base impositiva del ingreso individual, exceptuando los movimientos en la bolsa de valores. Además, para 2007 las reducciones de las tasas tope del ISR empresarial y personal, alrededor del 28\% (Sobarzo, 2007). Finalmente, la reforma del 2014 que contempla un aumento escalonado del ISR para personas físicas donde se acordó una tasa de $30 \%$ para los que ganen hasta 500 mil pesos al año, de 500 mil a 750 mil 31\%; de 750 mil a un millón $32 \%$; de 1 a 3 millones 34\%, y más de 3 millones de pesos pagarán 35\%. Sin embargo, estas modificaciones han mostrado tener un alcance bastante limitado que, aunado a la evasión y elusión fiscal, implican importantes pérdidas recaudatorias que impiden una adecuada redistribución del ingreso y, por ende, un menor gasto social.

Diversos estudiosos se han enfocado a investigar cómo incrementar la recaudación de los gobiernos especialmente en aquellos que presentan importantes índices de desigualdad económica, por ejemplo, Minzer, Pérez y Solís (2014) que han concluido que un aumento del ISR al noveno y décimo decil permite obtener un mayor incremento de recursos tributarios, además, que al ser la medida progresiva como lo demuestran en su investigación su efecto recae sólo en los dos deciles de más alto ingreso.

Casares et al. (2015) exponen la necesidad de una reforma tributaria, proporcionando una idea de las tasas de impuestos que implicaría en México un incremento sensible en la recaudación y, a su vez, una mejora en la distribución del ingreso. A través de un modelo de equilibrio general aplicado encontraron que, debido a la concentración del ingreso, las bases tributarias disponibles son demasiado estrechas, lo que implicaría aumentar sustancialmente las tasas efectivas, que podrían resultar poco factibles en el corto y mediano plazo.

De acuerdo con Bird y Zolt (2014) entre mayor sea la carga fiscal de un país, el potencial para incidir en la redistribución del ingreso también será mayor. Bajo esta idea, los autores argumentan que, si el ISR fuese usado para influir en la redistribución del ingreso, los países en desarrollo serían poco equitativos. Además, encontraron que, para la anterior década, el ISR fue del 38,6\% de la recaudación total en los países desarrollados, mientras que en los países en 
desarrollo fue de $24,3 \%$, de las cuales las dos terceras partes corresponden a las empresas. Ahora bien, como proporción del PIB, el ISR para personas físicas en países desarrollados fue de 7,2\% mientras que para países en desarrollo fue de 1,9\%.

Goñi, López y Servin (2008) analizaron las estructuras tributarias para Argentina, Brasil, Chile, Colombia, México y Perú para mediados del 2000, encontrando que éstas, junto a las transferencias redujeron el índice de Gini promedio de 0,52 a 0,50 , mientras que para 15 economías europeas el índice de Gini promedio se redujo de 0,46 a 0,27.

Finalmente, Aguilar y Lagunas (2016), compararon los resultados en la recaudación del ISR y del IVA en México, antes y después de la reforma fiscal que entró en vigor en 2014, concluyendo que, en relación con el ISR, la reforma fiscal no tuvo un efecto significativo, pero en relación con el IVA la reforma permitió que tanto los estados más grandes como los de menor recaudación elevaran su eficiencia tributaria.

La importancia de este estudio recae en el hecho de que dado el momento del diseño e implementación de cualquier tipo de política social en el que se debe adjudicar un presupuesto, junto con ésta se debe abordar la fuente de financiamiento que mantenga el presupuesto equilibrado y, especialmente, determinar ex-ante los posibles efectos económicos y sociales que traerían consigo dicha política. Además, buscar el bienestar social debe ser uno de los principales puntos de las agendas gubernamentales.

Esta investigación se divide en cuatro secciones: en la segunda sección se encuentra definida la metodología aplicada en cada uno de los análisis planteados y la base de datos usada para los diferentes análisis. La tercera sección presenta los resultados de cada uno de los escenarios alternativos propuestos, incluyendo un análisis del impacto del combate a la pobreza sobre la desigualdad y los índices de pobreza, para así compararlos entre sí. Finalmente, la cuarta sección incluye las principales conclusiones.

\section{Metodología y base de datos.}

La metodología seleccionada para comparar los efectos de cada uno de los escenarios alternativos propuestos hace parte de los llamados MLEG. Estos modelos han demostrado en diferentes investigaciones que son adecuados para analizar diversos tipos de políticas públicas como lo son los programas de TMC para el combate a la pobreza, así como lo ha hecho Sadoulet, Janvry y Davis (2001) quienes estudian el programa PROCAMPO a través de multiplicadores de ingreso, encontrando que estos tienen efectos multiplicadores cuando los receptores ponen a trabajar el dinero que reciben para generar ingresos adicionales. Asimismo, Núñez (2003) analiza transferencias a través de un análisis de sendas; Yúnez y González (2008) estiman a partir de un enfoque multisectorial los efectos en el ingreso de los hogares rurales y en la pobreza rural que podrían traer consigo cambios en sus actividades productivas a través de multiplicadores contables aplicados a una matriz de contabilidad social (MCS) agregada de diez comunidades rurales mexicanas caracterizadas por la pobreza.

Domínguez (2009) aplica un MLEG para analizar los efectos del programa Oportunidades, el programa de Atención al Adulto Mayor (PAAM) y el programa de Apoyo para las Personas con Discapacidad (PAPD) en el Estado de Nuevo León. Aguayo, Chapa y Rangel (2009) analizan el programa Oportunidades para el año 2004. González-Andrade y Fuentes-Flores (2010) analizan con un enfoque multisectorial el impacto multiplicativo en el ingreso y en la disminución de la pobreza de los hogares rurales provocado por un aumento exógeno de 100 pesos per cápita en las actividades productivas rurales. Aunque no analizan directamente un programa social, su simulación es similar a lo que sucedería con una TMC. Rodríguez y Morales (2014) analizan el impacto de las TMC de Oportunidades en Santo Domingo Yanhuitlán, economía rural, evaluando el efecto sobre el combate a la pobreza en el corto y largo plazo, aplicando modelos multisectoriales basados en MCS. 
Por lo que, los MLEG muestran el impacto que genera cualquier política económica en la economía, especialmente los efectos directos, indirectos e inducidos en cada uno de los sectores inter-industrial e institucional que la componen.

Cualquier tipo de política económica no solamente afecta al sector al cual ha sido dirigida, sino que desencadena una serie de efectos que repercuten en los diferentes mercados. Por lo tanto, una práctica adecuada del policymaker es verificar los efectos que ocasiona tanto en los agentes en los que incide directamente como los efectos producidos en todos los sectores, siendo una metodología adecuada los MLEG.

Estos modelos permiten captar todas las interdependencias entre los sectores interindustriales e institucionales de una economía; en particular, los efectos producidos en las variables endógenas debido a un cambio en una variable exógena, usando multiplicadores. Esto gracias al modelo Insumo-Producto (MIP) desarrollado por Leontief (1941), con el cual se llevó al campo empírico la teoría desarrollada por Walras. Los MLEG asumen los precios como exógenos y se analiza partiendo de las relaciones contables que se derivan de la MCS similar a la MIP, pero más completa ya que, la MCS tiene en cuenta el flujo circular de la renta, permitiendo captar los efectos desde los sectores productivos hacia los sectores receptores de rentas.

Para plantear estos modelos, siguiendo a Stone (1978) y Pyatt y Round (1979), primero se definen las cuentas que se consideran exógenas. A continuación se define una variación en las cuentas exógenas y se observa qué sucede con el resto de cuentas que constituyen el total de la economía. Las cuentas exógenas son las que se determinan fuera del sistema económico y representan posibles instrumentos de política económica ${ }^{4}$.

Una vez clasificadas las cuentas entre endógenas y exógenas, se procede a construir la matriz de propensiones medias al gasto $\left(A_{m m}\right)$. Esta resulta de dividir la matriz $Y_{m m}$ y $X_{k m}$ entre el total de la columna. $A_{m m}$ recoge los pagos realizados a la cuenta $i$ por cada unidad de ingreso de $j$, de la siguiente manera:

$$
a_{i j}=\frac{Y_{i j}}{Y_{j}}, \quad i, j=1, \ldots, n
$$

A continuación, se agrega un vector de componentes exógenos representado por $X_{A}, X_{F}$, $X_{P}$ y $X_{K}$; un vector que representa el nivel de ingresos de las cuentas endógenas representado por $Y_{A}, Y_{F}, Y_{P}$ y $Y_{K}$, y finalmente, un vector de pagos de las cuentas endógenas a las exógenas $P_{A}, P_{F}$, $P_{P}$ y $P_{K}$.

Resultando:

$$
Y_{i}=\sum_{j=1}^{n}\left(\frac{Y_{i j}}{Y j}\right) Y_{j}=\sum_{j=1}^{m} a_{i j} Y_{j}+\sum_{j=m+1}^{m+k} ; \quad n=m+k
$$

Donde, $m$ y $k$ son las cuentas endógenas y exógenas respectivamente. La ecuación anterior también se puede expresar como sigue:

\footnotetext{
${ }^{4}$ Como se mencionaba anteriormente, el modelo descrito ha sido ampliamente utilizado en diferentes estudios, y con el objetivo de ampliar la información con respecto a la metodología usada, se recomienda seguir a Lima et al. (2005), Cámara (2008), Campoy-Muñoz, Cardenete y Delgado (2017) y Cardenete y Delgado (2013).
} 


$$
\left[\begin{array}{c}
Y_{A} \\
Y_{F} \\
Y_{P} \\
Y_{K}
\end{array}\right]=\left[\begin{array}{cccc}
C_{I} & 0 & C_{F} & I \\
W & 0 & 0 & 0 \\
0 & R & T & 0 \\
0 & 0 & S & 0
\end{array}\right] \cdot\left[\begin{array}{c}
Y_{A} \\
Y_{F} \\
Y_{P} \\
Y_{K}
\end{array}\right]+\left[\begin{array}{c}
X_{A} \\
X_{F} \\
X_{P} \\
X_{K}
\end{array}\right]
$$

Finalmente, la matriz queda dividida en cuatro submatrices $A_{m m}, A_{m k}, A_{k m} y A_{k k}$, quedando de la siguiente manera:

$$
Y_{m}=A_{m m} Y_{m}+A_{m k} Y_{k}
$$

$Y_{m}$ y $Y_{k}$ representan los ingresos totales tanto de las cuentas endógenas como de las exógenas y $A_{m m}$ corresponde a las actividades productivas, que son los coeficientes técnicos que se obtienen con la MIP. Ahora, se despeja $Y_{m}$ y queda la ecuación matricial así:

$$
\begin{gathered}
Y_{m}=\left(I-A_{m m}\right)^{-1} \cdot A_{m k} \cdot Y_{k} \\
Y=M \cdot X_{m}
\end{gathered}
$$

Donde $\left(I-A_{m m}\right)^{-1}$ es llamada $M$ y es la matriz de multiplicadores lineales (ML); esta matriz muestra el impacto que genera un aumento unitario en las cuentas exógenas sobre las rentas de cada una de las cuentas endógenas. En otras palabras, indica las cuentas que generan mayores efectos expansivos en los ingresos de la economía total. Por otro lado, se tiene a $A_{m k} . Y_{k}$ como $X_{m}$ y representa las inyecciones de ingreso emitidas por las cuentas exógenas y recibidas por las endógenas ${ }^{5}$.

Asimismo, se busca analizar el impacto de las propuestas sobre la desigualdad y la pobreza. Para el primero se utiliza el coeficiente de Gini y, para el segundo, se utiliza el índice Foster, Greer y Thorbecke (FGT) (Foster, Greer \& Thorbecke, 1984), para determinar las condiciones de pobreza en las que se encuentra la población en estudio, así como sus carencias en los niveles de consumo individual.

El índice FGT, es un índice de carencias en el consumo privado, que toma como referencia una determinada línea de pobreza individual, como lo es un salario mínimo diario de la población total y de la población económicamente activa. A partir de esta se calcula la proporción de la población en condiciones de pobreza extrema ${ }^{6}$. Valores superiores del índice FGT reflejan un deterioro en el nivel de satisfacción del consumo individual.

Representado por:

$$
P_{\propto}=\left(\frac{1}{n}\right) \sum_{i=1}^{q}\left(\frac{z-x_{i}}{z}\right)^{\propto} ; \quad \propto \geq 0
$$

Donde, $\alpha$ es un parámetro que especifica la sensibilidad del índice, z es la línea de pobreza, $\mathrm{n}$ es el número total de hogares, xi es el ingreso del hogar i-ésimo, q es el número de hogares pobres, z-xi es la brecha de pobreza del i-ésimo hogar y (z-xi)/z la estandarización de la brecha de pobreza del i-ésimo hogar.

\footnotetext{
${ }^{5}$ Para la modelización fue usado el Software SimSipSam creado para el Banco Mundial por Parra y Wodon (2009). A partir de esta herramienta y la base teórica especificada anteriormente, es posible replicar las simulaciones realizadas en esta investigación.

${ }^{6}$ La pobreza extrema se define como el número de habitantes cuyo ingreso se encuentra por debajo de la línea de pobreza sobre la población total.
} 
$\propto=0$ es el porcentaje de personas en pobreza monetaria. $\propto=1$ es la brecha de pobreza, o el porcentaje promedio en el que los pobres deberán aumentar sus ingresos para superar la pobreza. $\propto=2$ constituye la medida más interesante, una medida de la severidad de la pobreza, o la distribución de los gastos per cápita entre los pobres. El índice FGT se expresa como una combinación de una medida de desigualdad, y la razón de la brecha del ingreso en una forma similar a la de Sen (2000). Además, está generalizada a una familia de medidas paramétricas donde el parámetro puede ser interpretado como un indicador de aversión a la pobreza.

Finalmente, como medida de desigualdad de ingresos, se toma el Índice de Gini. Éste varía entre 0 y 1 , donde 0 indica perfecta igualdad, es decir, todos los individuos poseen los mismos ingresos. Por el contrario, un valor de 1 hace referencia a perfecta desigualdad, es decir, solo un individuo posee todos los ingresos y los demás no poseen ninguno.

El cálculo del Índice de Gini para esta investigación, se realiza para datos agrupados (Medina, 2001): primero se ordenan los hogares en forma ascendente conforme a su ingreso; posteriormente, se definen intervalos de igual tamaño, que para este caso corresponden a deciles de ingresos, donde cada grupo deberá concentrar el 10\% de las observaciones.

Una vez definida esta información, se procede a calcular el Índice de Gini a partir de una de las expresiones que existe para datos agrupados:

$$
C G=1-\sum_{i=1}^{n} x_{i}\left(Y_{i}+Y_{i+1}\right)
$$

Donde, $n$ representa el número de grupos, $x_{i}$ es el porcentaje de población en el grupo i y $Y_{i}$ es el ingreso acumulado en el grupo $i$.

Como base de datos para los diferentes escenarios alternativos propuestos, se usa una MCS construida para México, llamada MCS-MX08 por Beltrán, Cardenete, Delgado y Núñez (2016).

Para realizar la primera simulación correspondiente al incremento del IVA de 2\% para ser destinado al combate a la pobreza, se usa la MCS-MX08, endogeneizando la cuenta de impuestos sobre los bienes y servicios. Por lo tanto, se consideran 36 cuentas endógenas y 6 cuentas exógenas. De acuerdo a Cardenete y Delgado (2011), las cuentas endógenas corresponden a las actividades productivas, remuneraciones a los factores productivos (trabajo y capital), sociedades y los hogares. Las cuentas exógenas corresponden al gobierno, la cuenta de capital y el resto del mundo. Se usa esta endogeneización debido a que es la cuenta a la que se le quiere aplicar el shock.

Para el caso de la segunda y tercera simulación, se usa la MCS-MX08 considerando 35 cuentas endógenas y 6 cuentas exógenas.

\section{Análisis y resultados.}

En este apartado se presentan los efectos económicos del impacto realizado con cada uno de los escenarios alternativos, seguido de sus efectos sobre la desigualdad y el índice de pobreza de acuerdo con FGT (1984). Por último, es presentado un comparativo entre cada uno de los resultados, con el fin de encontrar la combinación con mayor impacto positivo a la economía mexicana.

La primera simulación se basa en la propuesta realizada por el Gobierno Federal sobre un impuesto general a las ventas y servicios del $2 \%$ para combatir la pobreza como parte de una iniciativa de la Ley de Ingresos del Presupuesto de Egresos de la Federación para el Ejercicio del 
2010. Esta ley tenía como nombre "Ley de la Contribución para el Combate a la Pobreza"7. Su objetivo radicaba en la creación de un impuesto al consumo que permitiera una mayor recaudación para inyectar con más fondos a los programas sociales que benefician a los hogares pobres. El planteamiento sugerido para esta investigación retoma las ideas de esta propuesta realizada para el 2010 pero, definido no como un nuevo impuesto sino como un aumento del 2\% del IVA pasando este del 16\% al 18\% manteniendo su estructura inicial, con el fin de que no se graven los alimentos y las medicinas y no afecte el poder de compra y por ende la demanda de bienes y servicios de la población.

La segunda simulación se basó en Fuentes (2012), quien afirma que una forma de evasión es el uso de efectivo, ya que complica la identificación de su origen, debido a su carácter libre y anónimo. Las transacciones realizadas con este medio de pago no son rastreables o fácilmente identificables convirtiéndose en una razón para la evasión de impuestos. Para el 2008, que corresponde al año base de estudio, los IEUE corresponde a 171.948 millones de pesos mexicanos (9.050 millones de dólares americanos), que como proporción del Producto Interno Bruto (PIB) representa el 1,41\%. La propuesta de esta investigación busca responder al interrogante ¿qué pasaría si se lograra recaudar dicho monto de la evasión de impuestos debido al uso de efectivo, con el objetivo de ser utilizado para el combate a la pobreza?

Finalmente, la tercera simulación corresponde a la reforma fiscal para el 2014 aprobada el 31 de octubre del 2013 que propone entre otras reformas fiscales, un aumento del ISR para personas físicas que va de un $30 \%$ a un $35 \%$ escalonado en tres renglones adicionales de la siguiente manera:

A partir de los 750.000,01 pagarán 32\%, a partir de 1.000.000,01 pagarán 34\% y a partir de los 3.000.000,01 pagarán el 35\%. La propuesta radica en que este recaudo del 5\% adicional realizado se podrá destinar para el combate a la pobreza ${ }^{8}$.

En general, los procesos de reformas fiscales suelen ser complicados, ya que llevan implícitos costos que restan efectividad (CEEY, 2013). Las propuestas presentadas en esta investigación, en especial la relacionada con la recaudación de lo evadido por manejo de efectivo, implicaría realizar diferentes ajustes por parte del gobierno que supondrían unos costos para la administración tributaria, situación que se sale del alcance de esta investigación.

Si se lograra evitar la evasión de impuestos, simplemente con lo recaudado por IVA e ISR, podría ser posible cubrir el gasto social en México respecto a educación, salud, combate a la pobreza, entre otros, incluyendo un 3\% adicional para invertir en infraestructura. Actualmente, con la recaudación posible se cubre solo el $80 \%$ del gasto social y no se alcanza a invertir en infraestructura; sin embargo, para lograr una mejor recaudación de impuestos, el gobierno se presenta con una restricción relacionada con la cantidad y calidad de dinero que se necesitaría para recolectar los impuestos y para aplicar la ley tributaria. El tener un sistema tributario complejo eleva los costos de recaudación. Actualmente no hay estimaciones de cuánto se podría gastar, sin embargo, se estima que podría ser de 10 centavos por cada peso recaudado (CEEY, 2012).

La medición de la pobreza a partir de los diferentes escenarios alternativos se efectúa considerando el ingreso recibido. El superávit generado se usa para financiar el combate a la pobreza, ya sea con transferencias directas a los hogares pobres o a través de transferencias a la salud y a la educación, con lo que se resalta la idea de una reforma fiscal progresiva en México.

De acuerdo con Huesca y Araar (2016) una mejora en el sistema fiscal representa una herramienta más eficiente y efectiva para mejorar la distribución de la riqueza, haciendo posible

\footnotetext{
${ }^{7}$ Para más información ver Jiménez (2009).

${ }^{8}$ De acuerdo al informe de la KPMG (2013).
} 
que los impuestos sean más progresivos. Para México la evasión de impuestos se ha convertido en un fenómeno creciente debido a la expansión del sector informal, lo que exhibe la necesidad de una reforma fiscal. Algunos países latinoamericanos como Brasil, Argentina y Uruguay, han mostrado una mayor progresividad de sus sistemas fiscales, lo que ha llevado a un aumento de los efectos redistributivos (Lustig, Pessino \& Scott, 2014). Araar (2008) encontró en un estudio para Canadá al analizar el impacto del sistema fiscal sobre el tamaño y el bienestar de las clases socioeconómicas en el periodo 1993-2005, que la progresividad del sistema fiscal permitió una reducción en el número de personas pobres y un aumento de la clase media.

Sin embargo, no siempre la progresividad en el sistema fiscal garantiza una mejor distribución de ingresos. Duncan (2010) encontró que, ante un sistema legal débil y la presencia de un amplio sector informal, la progresividad tributaria puede aumentar la desigualdad.

Por lo que, aunque en esta investigación se proponen algunas reformas fiscales destinadas al combate a la pobreza, es importante señalar que en las condiciones actuales del sistema fiscal mexicano podrían complicar sus resultados. Lustig, Pessino y Scott (2014) encontraron que, para Bolivia, México y Perú, sus sistemas fiscales presentaron los impactos más bajos en la reducción de la pobreza, mientras que Argentina, Uruguay y Brasil presentaron las mayores reducciones de la pobreza, además de tener los sistemas fiscales más progresivos. Asimismo, Scott (2014) encontró para el periodo 2008-2010 que el sistema fiscal mexicano está atrapado en lo que llamó "equilibrio de bajos ingresos y beneficios", donde los bajos ingresos tributarios no son el resultado de tasas de impuestos excepcionalmente bajas, sino que resultan de bajos niveles de productividad impositiva.

Los niveles de desigualdad y pobreza en México persisten aún con los programas de TMC que ya tienen más de 15 años de ser implementados. La distribución de ingresos en México presenta importantes distorsiones tanto en la manera como se pagan los impuestos como en la forma en que los hogares reciben asistencia social a través del sistema fiscal, sin embargo, es posible mejorar la redistribución de recursos a través de los sistemas fiscales utilizando políticas redistributivas basadas en compensaciones que han funcionado tanto en países desarrollados como en desarrollo (Huesca \& Araar, 2016).

Además de esto, el sector informal en México ha ganado mucho terreno; de acuerdo con las últimas estimaciones del INEGI para el 2016, la economía informal presenta una participación en el PIB de 22,6\%, donde, casi el 60\% de la población ocupada del país tiene trabajo en el sector informal. Ahora bien, Kumler, Verhogen y Frias (2013) y Dougherty y Escobar (2013) mencionan que el subregistro de los salarios de las empresas registradas para evadir impuestos, así como el alto empleo en el sector informal impactan en la eficiencia marginal de los impuestos, reflejándose en niveles bajos de recaudación de impuestos, que a su vez hace que el sistema impositivo, aunque sea progresivo, no incida positivamente en la desigualdad con el tiempo.

La débil estructura fiscal mexicana aunada al bajo crecimiento, han empujado a dirigir la política social hacia los sectores vulnerables de la población a través del gasto público en programas de TMC sin mayor éxito, situación reflejada en sus índices de pobreza y desigualdad. Sin embargo, ante un panorama con un amplio sector informal, una evasión de impuestos corporativos y un alivio inefectivo del impuesto a las sociedades como lo presenta la economía mexicana, se justifica la necesidad de mejorar el diseño de un sistema de beneficios tributarios. Dougherty y Escobar (2013) dan un buen ejemplo al respecto: un aumento en la carga impositiva sobre la producción o el consumo de bienes puede ser relevante para compensar a los contribuyentes, ante una situación dominante del sector informal.

\subsection{Aumento del $2 \%$ del IVA para ser destinado al combate a la pobreza.}

Para la simulación de un shock exógeno, primero se identifica el monto recaudado por concepto del IVA para el año 2012 de 579.987,50 millones de pesos mexicanos (30.526 millones 
de dólares americanos), de acuerdo con los ingresos ordinarios del gobierno federal, obtenidos de la cuenta de Hacienda Pública Federal para el año 2012. Seguido, se impacta en un 2\% adicional dicho monto, con el objetivo de que éste sea repartido equitativamente entre los tres deciles más pobres de la población, que, por lo general, es la población objetivo de los programas sociales. En el caso del Programa Oportunidades, estos tres deciles focalizan el 65,8\% de sus recursos.

De esta manera, si se aumentara en 2\% al IVA, para el año 2012 posiblemente se hubiese recolectado 11.599 millones de pesos mexicanos (610 millones de dólares americanos), que son asignados de acuerdo a la regla de reparto construida, basándose en los montos transferidos por el programa Oportunidades y según la prioridad asignada por el mismo, quedando el decil I con el $41,19 \%$ de importancia, el decil II con el 33,59\% y el decil III con el 25,23\%. Con los porcentajes definidos, se realiza la distribución propuesta, según se muestra en la Tabla 1.

Tabla 1. Asignación monto recaudado con el 2\% adicional del IVA en millones de pesos mexicanos.

\begin{tabular}{|c|c|r|}
\hline Cuentas & Participación \% & \multicolumn{1}{c|}{$\begin{array}{c}\text { Monto a } \\
\text { transferir }\end{array}$} \\
\hline Imp. ByS & & $11.599,75$ \\
\hline I & $41,19 \%$ & $4.777,4$ \\
\hline II & $33,59 \%$ & $3.895,96$ \\
\hline III & $25,23 \%$ & $2.926,38$ \\
\hline Total & $100 \%$ & $11.599,75$ \\
\hline
\end{tabular}

Fuente: Elaboración propia con base en la SHCP (2012).

Este monto ingresa en la economía como shock exógeno, distribuido entre los tres primeros deciles. En la Tabla 2 se observan los efectos económicos que tiene dicho shock sobre el desempeño de la economía y sobre la distribución de la renta.

El vector $Y$ representa el output total de la economía antes de aplicar el shock exógeno; $Y$ aumento $2 \%$ del IVA representa el output total de la economía después de haber impactado tanto la cuenta de Impuesto de Bienes y Servicios como las de los tres primeros deciles y, el vector \% de cambio después del shock, representa el cambio generado al comparar la economía real con la simulada.

Estos resultados muestran que al aumentar en 2\% el IVA y al transferirlo a los tres primeros deciles que corresponden a los hogares más pobres, se produce un impacto total en el output de la economía mexicana equivalente a 36.256 millones de pesos mexicanos (1.908 millones de dólares americanos), que representa un incremento de $0,17 \%$. Se observa que el sector más beneficiado corresponde a transportes, correos y almacenamiento (7) con una variación de 0,38\%, el sector generación, transmisión y distribución de energía eléctrica (3) con una variación de 0,33\%, el sector servicios de alojamiento temporal (17) con una variación de 0,29\%, servicios de esparcimiento cultural y deportivo (16) y servicios inmobiliarios (10) con porcentajes de cambio de $0,29 \%$ cada uno y otros servicios con un $0,28 \%$. Por obvias razones la cuenta de Impuesto sobre bienes y servicios (24) tiene el mayor impacto con un porcentaje de $2,73 \%$ seguida de los tres primeros deciles (27, 28 y 29) con porcentajes de cambio de 2,05\%, 1,28\% y 0,84\% respectivamente, ya que el impacto le favorece directamente debido a la recaudación de impuestos adicional del $2 \%$, posteriormente asignada entre los tres primeros deciles.

Los sectores menos favorecidos con este impacto son el de la construcción (4) con una variación de $0,01 \%$, actividades legislativas (19) con un porcentaje de $0,03 \%$, servicios educativos (14) con un 0,07\% y la minería (2), con una variación de 0,08\%. 
Tabla 2. Variación del producto total al aumentar el IVA un 2\% para combatir la pobreza (millones de pesos mexicanos).

\begin{tabular}{|c|c|c|c|}
\hline Cuenta & $\mathrm{Y}$ & $\begin{array}{l}\text { Y aumento } 2 \% \text { del } \\
\text { IVA }\end{array}$ & $\begin{array}{c}\% \text { de cambio } \\
\text { después del shock }\end{array}$ \\
\hline Agricultura, cría y explotación de animales & 586.319 & 587.202 & 0,14 \\
\hline Minería & 1.238 .359 & 1.239 .403 & 0,08 \\
\hline $\begin{array}{l}\text { Generación, transmisión y distribución de energía } \\
\text { eléctrica }\end{array}$ & 454.744 & 456.314 & 0,33 \\
\hline Construcción & 1.925 .713 & 1.925 .992 & 0,01 \\
\hline Industrias Manufactureras & 6.949 .142 & 6.959 .391 & 0,15 \\
\hline Comercio & 2.332 .613 & 2.337 .130 & 0,19 \\
\hline transportes, correos y almacenamiento & 1.152 .579 & 1.157 .489 & 0,38 \\
\hline Información en medios masivos & 487.363 & 488.665 & 0,25 \\
\hline Servicios financieros y de seguros & 598.298 & 599.762 & 0,24 \\
\hline Servicios inmobiliarios & 1.615 .425 & 1.620 .117 & 0,29 \\
\hline Servicios profesionales, científicos y técnicos & 402.904 & 403.703 & 0,17 \\
\hline Corporativos & 84.260 & 84.438 & 0,21 \\
\hline Servicios de apoyo a los negocios & 475.101 & 476.028 & 0,19 \\
\hline Servicios educativos & 539.239 & 539.655 & 0,07 \\
\hline Servicios de salud y de asistencia social & 362.835 & 363.254 & 0,09 \\
\hline Servicios de esparcimiento culturales y deportivos & 74.044 & 74.260 & 0,29 \\
\hline Servicios de alojamiento temporal & 399.154 & 400.322 & 0,29 \\
\hline Otros servicios & 346.327 & 347.359 & 0,28 \\
\hline Actividades legislativas & 658.148 & 658.341 & 0,03 \\
\hline Trabajo & 2.805 .315 & 2.809 .338 & 0,14 \\
\hline Contribuciones sociales efectivas a la seguridad social & 415.285 & 415.735 & 0,11 \\
\hline Otras prestaciones sociales & 203.675 & 203.952 & 0,14 \\
\hline Capital & 7.488 .572 & 7.503 .564 & 0,2 \\
\hline Impuestos Bienes y Servicios & 315.664 & 328.664 & 2,73 \\
\hline Sociedades & 7.488 .572 & 7.503 .564 & 0,2 \\
\hline Consumo Privado & 7.030 .758 & 7.052 .357 & 0,31 \\
\hline Hogar en el decil I & 251.377 & 256.540 & 2,05 \\
\hline Hogar en el decil II & 345.116 & 349.542 & 1,28 \\
\hline Hogar en el decil III & 429.525 & 433.123 & 0,84 \\
\hline Hogar en el decil IV & 515.125 & 515.949 & 0,16 \\
\hline Hogar en el decil V & 599.226 & 600.199 & 0,16 \\
\hline Hogar en el decil VI & 729.984 & 731.179 & 0,16 \\
\hline Hogar en el decil VII & 836.642 & 837.999 & 0,16 \\
\hline Hogar en el decil VIII & 1.060 .989 & 1.062 .746 & 0,17 \\
\hline Hogar en el decil IX & 1.471 .878 & 1.474 .346 & 0,17 \\
\hline Hogar en el decil $X$ & 3.000 .835 & 3.006 .052 & 0,17 \\
\hline Total & 55.671 .107 & 55.803 .672 & 0,17 \\
\hline
\end{tabular}

Fuente: Elaboración propia basada en la MIP total doméstica 2008 publicada por el INEGI (2013) siguiendo a Cardenete, Delgado y Fuentes (2013). 


\subsection{Impacto sectorial de un $1,41 \%$ del PIB recaudado por la evasión de impuestos en el crecimiento y el precio para el 2008.}

La propuesta del caso hipotético radica en que el superávit presentado sea invertido en salud y educación ${ }^{9}$, con el fin de analizar los efectos redistributivos que se generan, en lugar de impactar directamente a los hogares.

Para esto, primero se determina el IEUE para el año 2008, que según Fuentes (2012) es de 171.948 millones de pesos mexicanos (9.050 millones de dólares americanos), suponiendo que este pueda ser recaudado y transferido a los sectores de salud y educación. Según la regla de reparto, se destina el 57,05\% para salud y el 42,95\% para educación, de acuerdo con los montos que el gobierno destina para cada uno de estos sectores (SHCP, 2008). Seguido, se distribuye el monto evadido como lo muestra la Tabla 3.

Tabla 3. Asignación monto evadido por manejo de efectivo (millones de pesos mexicanos).

\begin{tabular}{|c|c|r|}
\hline Cuentas & Participación \% & Monto a Transferir \\
\hline Salud & $57,05 \%$ & $98.096,19$ \\
\hline Educación & $42,95 \%$ & $73.851,81$ \\
\hline Total & $100 \%$ & $171.948,00$ \\
\hline
\end{tabular}

Fuente: Elaboración propia a partir de datos de la SHCP (2008).

En este caso, la obtención del vector $X$ que representa las inyecciones totales que las cuentas endógenas reciben de las cuentas exógenas, se realiza mediante la suma de todas las inyecciones de ingresos procedentes de la recaudación de impuestos por evasión por manejo de efectivo, que son transferidos a los sectores salud y educación. Posteriormente se determina el vector $\Delta Y$ que corresponde al producto total de las cuentas endógenas cuando se le aplica un shock positivo a la economía mexicana.

En la Tabla 4 se observa al vector $X$ que contiene todas las inyecciones provenientes de la recaudación del IEUE hacia los sectores de salud y de educación, el vector XtransSyE que incluye estas inyecciones, el vector $Y$ que contiene los productos totales de las cuentas endógenas considerando el monto recaudado, y el vector YconTransSyE que contiene los productos totales de las cuentas endógenas cuando son transferidos dichos montos. Por último, el porcentaje de variación desde un escenario con transferencias hacia uno sin transferencias.

Se observa que el output total de la economía mexicana tras el impacto propuesto aumenta un 2,27\% correspondiente a un valor de 482.014 millones de pesos mexicanos (25.369 millones de dólares americanos), produciendo un impacto del 6,09\% en las contribuciones sociales efectivas a la seguridad social y un aumento del 3,63\% en el trabajo. Por otro lado, el consumo privado aumenta un $2,76 \%$ al igual que los hogares, especialmente los cuatro deciles más altos con porcentajes de cambio que van desde el 2,85\% (decil X) al 2,95\% (decil IX). Un resultado interesante de esta simulación es que los hogares menos favorecidos o aquellos que se encuentran en los deciles más bajos, efectivamente aumentan su output total, pero en menor proporción que los deciles más altos de la economía.

\footnotetext{
${ }^{9}$ Diferentes investigaciones (López-Acevedo y Salinas, 2000; Banco Mundial, 2004; Programa de las Naciones Unidas para el Desarrollo, 2011) han demostrado que las TMC, el gasto en salud y el gasto en educación Primaria y Secundaria reducen la desigualdad en el ingreso, a pesar, de que la educación Superior tiende a ser regresiva.
} 
Tabla 4. Variación del producto total por transferencias para educación y salud (millones de pesos mexicanos).

\begin{tabular}{|c|c|c|c|c|c|}
\hline Cuenta & $x$ & XTransfSyE & Y & TTransfSyE & $\begin{array}{c}\% \text { de cambio } \\
\text { después del shock }\end{array}$ \\
\hline Agricultura, cría y explotación de animales & 184.881 & 184.881 & 615.085 & 622.121 & 1,14 \\
\hline Minería & 618.782 & 618.782 & 1.243 .710 & 1.251 .860 & 0,66 \\
\hline $\begin{array}{l}\text { Generación, transmisión y distribución de } \\
\text { energía eléctrica }\end{array}$ & 28.312 & 28.312 & 476.138 & 488.664 & 2,63 \\
\hline Construcción & 1.792 .012 & 1.792 .012 & 1.934 .131 & 1.935 .817 & 0,09 \\
\hline Industrias Manufactureras & 2.701 .265 & 2.701 .265 & 6.956 .946 & 7.050 .340 & 1,34 \\
\hline Comercio & 525 & 525.303 & 2.337 .524 & 2.379 .148 & 1,78 \\
\hline transportes, correos y almacenamiento & 331.072 & 331.072 & 1.280 .240 & 1.304 .261 & 1,88 \\
\hline Información en medios masivos & 44.815 & 44.815 & 521.764 & 534.689 & 2,48 \\
\hline Servicios financieros y de seguros & 49.095 & 49.095 & 621.080 & 634.498 & 2,16 \\
\hline Servicios inmobiliarios & 55.937 & 55.937 & 1.622 .241 & 1.664 .674 & 2,62 \\
\hline $\begin{array}{l}\text { Servicios profesionales, científicos y } \\
\text { técnicos }\end{array}$ & 83.056 & 83.056 & 463.408 & 474.491 & 2,39 \\
\hline Corporativos & 330.000 & 330 & 84.408 & 86.200 & 1,9 \\
\hline Senvicios de apoyo a los negocios & 634.000 & 634 & 475.735 & 486.346 & 2,23 \\
\hline Servicios educativos & 492.833 & 566.685 & 621.223 & 698.631 & 12,46 \\
\hline Servicios de salud y de asistencia social & 319.511 & 417.607 & 442.520 & 544.018 & 22,94 \\
\hline $\begin{array}{l}\text { Servicios de esparcimiento culturales y } \\
\text { deportivos }\end{array}$ & 6.075 & 6.075 & 74.361 & 76.227 & 2,51 \\
\hline Senvicios de alojamiento temporal & 1.816 & 1.816 & 400.969 & 411.735 & 2,68 \\
\hline Otros servicios & 23.620 & 23.620 & 369.947 & 379.849 & 2,68 \\
\hline Actividades legislativas & 662.835 & 662.835 & 665 & 665.057 & 0,01 \\
\hline Trabajo & 12.979 & 12.979 & 2.805 .315 & 2.907 .048 & 3,63 \\
\hline $\begin{array}{l}\text { Contribuciones sociales efectivas a la } \\
\text { seguridad social }\end{array}$ & 0 & 0 & 415.285 & 440.587 & 6,09 \\
\hline Otras prestaciones sociales & 0 & 0 & 203.675 & 208.180 & 2,21 \\
\hline Capital & 0 & 0 & 7.488 .572 & 7.665 .007 & 2,36 \\
\hline Sociedades & 0 & 0 & 7.488 .572 & 7.665 .007 & 2,36 \\
\hline Consumo Privado & 0 & 0 & 7.030 .758 & 7.225 .148 & 2,76 \\
\hline Hogar en el decil I & 49.678 & 49.678 & 251.377 & 256.552 & 2,06 \\
\hline Hogar en el decil II & 57.736 & 57.736 & 345.116 & 353.005 & 2,29 \\
\hline Hogar en el decil III & 57.411 & 57.411 & 429.525 & 440.095 & 2,46 \\
\hline Hogar en el decil IV & 54.237 & 54.237 & 515.125 & 528.369 & 2,57 \\
\hline Hogar en el decil $\mathrm{V}$ & 48.777 & 48.777 & 599.226 & 615.307 & 2,68 \\
\hline Hogar en el decil VI & 48.956 & 48.956 & 729.984 & 750.108 & 2,76 \\
\hline Hogar en el decil VII & 48.983 & 48.983 & 836.642 & 860.525 & 2,85 \\
\hline Hogar en el decil VIII & 44.623 & 44.623 & 1.060 .989 & 1.091 .634 & 2,89 \\
\hline Hogar en el decil IX & 39.057 & 39.057 & 1.471 .878 & 1.515 .299 & 2,95 \\
\hline Hogar en el decil $X$ & 59.121 & 59.121 & 3.000 .835 & 3.086 .401 & 2,85 \\
\hline Total & 8.443 .743 & 8.615 .691 & 55.879 .490 & 57.296 .901 & 2,27 \\
\hline
\end{tabular}

Fuente: Elaboración propia basada en la MIP total doméstica 2008 publicada por el INEGI (2013).

Al mismo tiempo, los sectores productivos con mayor impacto positivo en la redistribución de la renta son salud y educación, con porcentajes de cambio de 22,94\% y 12,46\% respectivamente, debido a que son los sectores que reciben el impacto exógeno directamente. Asimismo, entre otros sectores favorecidos se tienen a los servicios de alojamiento temporal y otros servicios con porcentajes de cambio de 2,68\%, generación, transmisión y distribución de energía eléctrica con un 2,63\%, servicios inmobiliarios con una variación de 2,62\% y servicios de esparcimiento cultural con un 2,51\%. 
No obstante, los sectores menos favorecidos son actividades legislativas con una variación de $0,01 \%$, construcción con un $0,09 \%$, minería con 0,66\% y agricultura, cría y explotación de animales con un $1,14 \%$.

\subsection{Aumento del $5 \%$ del ISR a personas físicas destinados al combate de la pobreza.}

Igualmente, en esta simulación se parte del vector que representa el shock exógeno aplicado a la economía. El monto de impacto equivale a 760.104 millones de pesos mexicanos (40.005 millones de dólares americanos) de acuerdo con la Tabla 1. El superávit presentado con la reforma del 5\% aplicando la escala actual de recaudación del ISR, se distribuye a partir del peso asignado por su incidencia en el ingreso bruto por deciles de hogares. En esta distribución se observa que el último decil soporta la mayor carga del ISR. La incidencia del ISR se calcula respecto al ingreso bruto total para cada decil de ingreso, considerando la distribución de todos los perceptores reportados en la Encuesta Nacional de Ingreso y Gasto de los Hogares (ENIGH) ${ }^{10}$.

Esta información muestra que el decil I no aporta al ISR mientras que el decil X es el que mayor aporte ejerce con un 53,5\%. Ahora bien, se le aplica al ISR recaudado total un 5\% adicional para ser distribuido de acuerdo con la regla de reparto presentada en la Tabla 3. Para crear el vector de shock exógeno, se reparte el 5\% adicional al monto recaudado, con un superávit total de 38.005,20 millones de pesos mexicanos (2.000 millones de dólares americanos), como se muestra en la Tabla 5.

Tabla 5. Vector de shock exógeno (millones de pesos mexicanos).

\begin{tabular}{|c|c|r|}
\hline Cuentas & Participación \% & Monto a Transferir \\
\hline ISR & & $38.005,20$ \\
\hline I & $41,19 \%$ & $15.652,60$ \\
\hline II & $33,59 \%$ & $12.764,66$ \\
\hline III & $25,23 \%$ & $9.587,94$ \\
\hline Total & $100 \%$ & $38.005,20$ \\
\hline
\end{tabular}

Fuente: Elaboración propia con base en la SHCP (2012).

La Tabla 6 incluye al vector $Y$ que contiene los outputs totales de las cuentas endógenas considerando el monto recaudado, y al vector YconTransferencia que contiene los outputs totales de las cuentas endógenas cuando se ingresan dichos montos. Por último, se incluye el porcentaje de variación desde un escenario con transferencia hacia uno sin transferencia.

Al transferir un 5\% adicional a la economía mexicana por el aumento del ISR, el output total de la economía aumenta un 0,38\% que corresponde a 81.099 millones de pesos mexicanos (4.268 millones de dólares americanos). El sector productivo con mayor impacto corresponde a servicios de esparcimiento cultural con una variación de 0,76\%, seguida de servicios de alojamiento temporal y servicios inmobiliarios con un $0,74 \%$ cada uno, y otros servicios con un 0,69\%. El sector productivo con menor impacto corresponde a construcción y a actividades legislativas que no presentan variación, seguida de servicios educativos y minería con un $0,17 \%$ de variación respectivamente.

\footnotetext{
${ }^{10}$ Para más información revisar SHCP (2012).
} 
Tabla 6. Variación del producto total al ingresar el monto recaudado por un aumento del $5 \%$ del ISR para personas físicas en millones de pesos mexicanos.

\begin{tabular}{|c|c|c|c|}
\hline Cuenta & $\mathrm{Y}$ & YconTransferencias & $\begin{array}{c}\% \text { cambio después } \\
\text { del shock }\end{array}$ \\
\hline Agricultura, cría y explotación de animales & 615.085 & 617.055 & 0,32 \\
\hline Minería & 1.243 .710 & 1.245 .858 & 0,17 \\
\hline $\begin{array}{l}\text { Generación, transmisión y distribución de energía } \\
\text { eléctrica }\end{array}$ & 476.138 & 478.627 & 0,52 \\
\hline Construcción & 1.934 .131 & 1.934 .198 & 0 \\
\hline Industrias Manufactureras & 6.956 .946 & 6.981 .682 & 0,36 \\
\hline Comercio & 2.337 .524 & 2.348 .772 & 0,48 \\
\hline transportes, correos y almacenamiento & 1.280 .240 & 1.287 .047 & 0,53 \\
\hline Información en medios masivos & 521.764 & 525.079 & 0,64 \\
\hline Servicios financieros y de seguros & 621.080 & 624.888 & 0,61 \\
\hline Servicios inmobiliarios & 1.622 .241 & 1.634 .279 & 0,74 \\
\hline Servicios profesionales, científicos y técnicos & 463.408 & 465.148 & 0,38 \\
\hline Corporativos & 84.590 & 84.970 & 0,45 \\
\hline Servicios de apoyo a los negocios & 475.735 & 477.873 & 0,45 \\
\hline Servicios educativos & 621.223 & 622.285 & 0,17 \\
\hline Servicios de salud y de asistencia social & 442.520 & 443.548 & 0,23 \\
\hline Servicios de esparcimiento culturales y deportivos & 74.361 & 74.924 & 0,76 \\
\hline Servicios de alojamiento temporal & 400.969 & 403.945 & 0,74 \\
\hline Otros servicios & 369.947 & 372.518 & 0,69 \\
\hline Actividades legislativas & 665.000 & 665.017 & 0 \\
\hline Trabajo & 2.805 .315 & 2.813 .821 & 0,3 \\
\hline $\begin{array}{l}\text { Contribuciones sociales efectivas a la seguridad } \\
\text { social }\end{array}$ & 415.285 & 416.274 & 0,24 \\
\hline Otras prestaciones sociales & 203.675 & 204.283 & 0,3 \\
\hline Capital & 7.488 .572 & 7.522 .995 & 0,46 \\
\hline ISR & 731.163 & 772.670 & 5,68 \\
\hline Sociedades & 7.488 .572 & 7.522 .995 & 0,46 \\
\hline Consumo Privado & 7.030 .758 & 7.089 .490 & 0,84 \\
\hline Hogar en el decil I & 251.377 & 267.910 & 6,58 \\
\hline Hogar en el decil II & 345.116 & 359.078 & 4,05 \\
\hline Hogar en el decil III & 429.525 & 440.625 & 2,58 \\
\hline Hogar en el decil IV & 515.125 & 516.979 & 0,36 \\
\hline Hogar en el decil V & 599.226 & 601.411 & 0,36 \\
\hline Hogar en el decil VI & 729.984 & 732.663 & 0,37 \\
\hline Hogar en el decil VII & 836.642 & 839.673 & 0,36 \\
\hline Hogar en el decil VIII & 1.060 .989 & 1.064 .918 & 0,37 \\
\hline Hogar en el decil IX & 1.471 .878 & 1.477 .393 & 0,37 \\
\hline Hogar en el decil $X$ & 3.000 .835 & 3.012 .556 & 0,39 \\
\hline Total & 55.610 .653 & 56.943 .446 & 0,38 \\
\hline
\end{tabular}

Fuente: Elaboración propia basada en la MIP total doméstica 2008 publicada por el INEGI (2013).

No obstante, las cuentas que mayor cambio presentan son la correspondiente al ISR con una variación de 6,68\%, los tres primeros deciles con porcentajes de cambio de 6,58\%, 4,05\% y $2,58 \%$ respectivamente, junto con consumo privado con un $0,84 \%$; esto se debe a que son las cuentas directamente impactadas y, por lo tanto, presentan mayor efecto absorción. 


\subsection{Impacto de los escenarios alternativos sobre la desigualdad y los índices de pobreza.}

En esta sección, se analiza el impacto de los diferentes escenarios alternativos propuestos sobre la desigualdad y los índices de pobreza. Cada escenario se analiza desde el punto de vista del coeficiente de Gini y el Índice FGT. Por último, se realiza una comparación entre las diferentes propuestas realizadas en esta investigación y el panorama real, para definir la reforma que mejores resultados arroja y que se recomienda ser tomada en cuenta como una política alternativa para el combate a la pobreza en México.

La Tabla 7 muestra el nivel de desigualdad presentado en los hogares mexicanos si se aplicara cada uno de los escenarios alternativos planteados anteriormente. Se observa que el decil $\mathrm{X}$ representa el 41,4\% del ingreso total de los hogares en México y el decil I apenas el 1.39\% del ingreso, reflejando una elevada concentración de ingresos que es confirmada con el coeficiente de Gini. A pesar de la inyección de recursos adicionales a los tres primeros deciles bajo la propuesta del aumento del IVA, la distribución del ingreso queda prácticamente en el mismo nivel presentado antes del cambio con una reducción mínima de 0,0008.

Por otro lado, al transferir recursos a la salud y la educación, la distribución del ingreso presenta un aumento mínimo de 0,0005. Finalmente, la propuesta del aumento del ISR arroja una disminución del coeficiente de Gini de 0,003, es decir, la economía mexicana bajo la implementación de las propuestas sugeridas y los datos reales observados siguen mostrando los mismos índices de desigualdad reflejando un entorno de inequidad relevante. Sin embargo, se observa que la propuesta que mejores efectos arroja es la relacionada con el ISR, a pesar de que estos sean marginales.

Tabla 7. Análisis de la distribución del Ingreso para México. Aumento del $2 \%$ del IVA para ser transferido a los hogares pobres, 2012.

\begin{tabular}{|c|r|r|r|r|r|r|r|r|}
\hline & & \multicolumn{7}{|c|}{ Ingreso trimestral promedio por habitante (MXN) } \\
\cline { 3 - 9 } Decil & $\begin{array}{c}\text { Participación } \\
\text { en el ingreso }\end{array}$ & $\begin{array}{c}\text { Sin } \\
\text { Transferencias }\end{array}$ & $\begin{array}{c}\text { Con transferencias } \\
\text { por el aumento del } \\
\text { IVA }\end{array}$ & $\begin{array}{c}\text { \% de } \\
\text { cambio }\end{array}$ & $\begin{array}{c}\text { Con transferencias } \\
\text { a la salud y } \\
\text { educación }\end{array}$ & $\begin{array}{c}\text { \% de } \\
\text { cambio }\end{array}$ & $\begin{array}{c}\text { Con transferencias } \\
\text { por el aumento del } \\
\text { ISR }\end{array}$ & $\begin{array}{c}\% \text { de } \\
\text { cambio }\end{array}$ \\
\hline I & 1,39 & $1.819,07$ & $1.846,64$ & 1,52 & $1.859,52$ & 2,22 & $1.906,77$ & 4,82 \\
\hline II & 2,49 & $3.250,84$ & $3.281,26$ & 0,94 & $3.228,99$ & 2,4 & $3.345,41$ & 2,91 \\
\hline III & 3,37 & $4.404,77$ & $4.432,27$ & 0,62 & $4.515,75$ & 2,52 & $4.487,78$ & 1,88 \\
\hline IV & 4,27 & $5.566,3$ & $5.592,48$ & 0,47 & $5.711,24$ & 2,6 & $5.643,01$ & 1,38 \\
\hline V & 5,28 & $6.885,08$ & $6.910,75$ & 0,37 & $7.069,16$ & 2,67 & $6.957,64$ & 1,05 \\
\hline VI & 6,55 & $8.541,4$ & $8.571,42$ & 0,35 & $8.773,63$ & 2,72 & $8.625,08$ & 0,98 \\
\hline VII & 8,33 & $10.875,02$ & $10.908,75$ & 0,31 & $11.175,14$ & 2,76 & $10.966,97$ & 0,85 \\
\hline VIII & 10,93 & $14.257,21$ & $14.298,82$ & 0,29 & $14.655,66$ & 2,79 & $14.369,36$ & 0,79 \\
\hline IX & 15,99 & $20.882,56$ & $20.918,37$ & 0,17 & $21.474,11$ & 2,83 & $20.964,64$ & 0,39 \\
\hline X & 41,4 & $53.939,88$ & $54.030,54$ & 0,17 & $55.485,5$ & 2,87 & $54.146,88$ & 0,38 \\
\hline \multicolumn{2}{|c|}{ Coeficiente de Gini } & 0.505618 & & 0,504733 & & 0,506183 & & 0,50271 \\
\hline
\end{tabular}

Fuente: Elaboración propia con datos de la ENIGH (2012).

Diferentes investigaciones han mostrado algunos resultados comparando el índice de Gini en diferentes procesos redistributivos, como Goñi, López y Servin (2008) quienes analizaron las estructuras tributarias para Argentina, Brasil, Chile, Colombia, México y Perú para mediados del 2000, encontrando que éstas junto a las transferencias redujeron el índice de Gini promedio de 0,52 a 0,50, mientras que para 15 economías europeas el índice de Gini promedio se redujo de 0,46 a 0,27 .

Campos-Vazquez, Esquivel y Lustig (2014) muestran el comportamiento del índice de Gini para el ingreso monetario disponible per cápita para México. Encuentran que para el periodo 
1989-1994, el índice sube y fluctúa. Para el periodo 1998-2010, el índice declina, con un aumento en el año 2008. En este estudio la reducción del índice de Gini se debe principalmente a la disminución de la desigualdad del ingreso laboral hasta el año 2000, cuando las transferencias del gobierno se perciben.

Casares et al. (2015) encuentran que lograr una recaudación adicional significativa y mejorar la desigualdad del ingreso medida a través del índice de Gini, implica aumentos de tasas bases difíciles de lograr en las condiciones actuales. Para esto plantean siete escenarios que consisten en duplicar tasas efectivas de IVA e ISR y hacer transferencias a los deciles I de diferentes maneras, con lo que encuentran que en todos los escenarios se ve mejorado el índice de Gini, especialmente cuando se hacen transferencias al decil I, a excepción del escenario dos donde se cancelan las transferencias.

También Azevedo, Inchaust y Sanfelice (2013) muestran para el periodo 2000-2010, un descenso del índice de Gini para América Latina, donde el factor que más contribuyó a ello fue el fuerte crecimiento de los ingresos laborales en los deciles más pobres.

A continuación, se presentan los resultados del impacto de las reformas sobre los índices de pobreza a través del Índice FGT. Para esto se calcula el índice FGT para $\alpha=0, \alpha=1$ y $\alpha=$ 2 bajo las condiciones presentadas en la economía para el año 2012. La variación de ingreso propuesto, es el resultado arrojado por la modelización anterior, teniendo en cuenta solo el cambio presentado en los hogares. En cuanto a las líneas de pobreza utilizadas, la referente a pobreza moderada es de 5.709,99 pesos mexicanos trimestrales (300 dólares americanos) y la de pobreza extrema es de 2.854,86 pesos mexicanos trimestrales (150 dólares americanos) para el 2012, obtenidos con el promedio de las líneas de pobreza rural y urbana, ya que la MCS construida no hace diferenciación entre estas. En la Tabla 8 se aprecian los resultados arrojados por el análisis, incluyendo todos los escenarios analizados.

Tabla 8. Comparativo entre los diferentes escenarios hipotéticos para el combate a la pobreza.

\begin{tabular}{|l|c|c|c|c|c|c|}
\hline \multirow{2}{*}{ Panorama } & \multicolumn{3}{c|}{ Pobreza Moderada } & \multicolumn{3}{c|}{ Pobreza Extrema } \\
\cline { 2 - 7 } & Head Count & P1 & P2 & Head Count & P1 & P2 \\
\hline Situación Real & 36,36 & 13,81 & 7,22 & 11,78 & 3,7 & 1,71 \\
\hline Sin Programa Oportunidades & 37,06 & 14,48 & 7,71 & 12,45 & 4,09 & 1,94 \\
\hline Aumento 2\% del IVA & 36,24 & 13,63 & 7,09 & 11,48 & 3,58 & 1,65 \\
\hline Transferencia Salud y Educación & 33,03 & 12,25 & 6,33 & 9,12 & 2,82 & 1,29 \\
\hline Aumento del 5\% al ISR & 35,75 & 13,27 & 6,81 & 10,9 & 3,35 & 1,52 \\
\hline
\end{tabular}

Fuente: Elaboración propia con base en la ENIGH (2012).

Con el análisis comparativo realizado a través del índice FGT, se observa que los niveles de pobreza disminuyen cuando se inyecta adicionalmente transferencias a la población, de acuerdo con la Tabla 8. Si se retiraran las TMC del programa oportunidades los niveles de pobreza aumentarían, pero si se realizaran inyecciones adicionales los niveles de pobreza disminuirían. Esta disminución varía según cada una de las propuestas. De manera agregada y de acuerdo con el caso hipotético de un aumento del 2\% del IVA, al considerar la pobreza moderada, el índice de incidencia presentaría una disminución del 0,12\%, el índice de intensidad disminuiría en 0,18\% y el índice de severidad disminuiría en 0,13\% pasando de 7,22\% a 7,09\%.

En cuanto a la pobreza extrema, de igual manera disminuirían sus índices, pero en menor medida que la pobreza moderada con excepción del índice de incidencia ya que esta muestra una disminución del $0,30 \%$, presentando una mayor reducción al compararla con la pobreza moderada. El cambio más significativo por importancia es el arrojado por el índice de severidad 
de la pobreza con una disminución de $0,06 \%$. Por otro lado, la brecha de la pobreza se reduce en $0,11 \%$.

Ahora bien, el escenario hipotético en el que se transfiere el 1,41\% con respecto al PIB recaudado por IEUE para ser transferido a salud y educación, toma en cuenta las condiciones presentadas en la economía para el año 2008, bajo el supuesto de que la economía no varía en un periodo de cinco años. En este caso se utiliza como línea de pobreza extrema el valor de 2.582,12 pesos mexicanos trimestrales (136 dólares americanos) y pobreza moderada el valor de 5.445,12 pesos mexicanos trimestrales (287 dólares americanos) correspondientes para el año 2008 pero a precios del 2012.

Con el análisis comparativo realizado a través del Índice FGT se observa que los niveles de pobreza disminuyen cuando se transfieren recursos hacia la salud y la educación. De manera agregada y considerando la pobreza moderada, el índice de incidencia presenta una disminución del 3,33\%, el índice de intensidad disminuye en 1,56\% y el índice de la severidad disminuye en $0,89 \%$ pasando de $7,22 \%$ a 6,33\%. En cuanto a la pobreza extrema, de igual manera disminuyen sus índices, pero en menor medida que la pobreza moderada, siendo el más significativo por importancia el índice de severidad de la pobreza con una disminución de $0,43 \%$. En cuanto a la población en pobreza extrema, estos disminuyen en 2,66\%.

Estos resultados muestran que aumentar los recursos para salud y educación trae mejores beneficios que si se realizaran transferencias en efectivo a la población en pobreza, a pesar de que, en la simulación anterior, individualmente los últimos deciles se veían más beneficiados que los primeros. Por lo tanto, una política social enfocada en el mejoramiento de la salud y la educación impactaría positivamente sobresaliendo ante las demás propuestas de transferencias en efectivo y contribuyendo con mejores resultados para el combate a la pobreza.

Por último, el escenario alternativo que consiste en el aumento del 5\% del ISR, para ser transferido a los tres primeros deciles de los hogares, disminuye los índices de pobreza cuando se transfieren recursos a los tres primeros deciles. De manera agregada y considerando la pobreza moderada, el índice de incidencia presenta una disminución del 0,61\%, el índice de intensidad disminuye en 0,54\% y el índice de severidad disminuye en $0,41 \%$ pasando de $7,22 \%$ a $6,81 \%$. La pobreza extrema, de igual manera disminuye sus índices, pero en menor medida que la pobreza moderada a excepción del índice de incidencia de la pobreza, con una disminución de $0,87 \%$. Por otro lado, el índice de severidad de la pobreza que resulta ser el más importante debido a que mide el nivel de desigualdad presentado entre la población pobre, muestra una variación de 0,19\%. Por último, el índice de intensidad de la pobreza extrema es de $0,35 \%$.

Al comparar todas las simulaciones, se concluye que el escenario que arroja mejores resultados para el combate a la pobreza resulta del aumento del 1,41\% en proporción del PIB a la salud y educación, seguida del aumento del 5\% del ISR para ser transferido a los tres primeros deciles de los hogares mexicanos. Este resultado muestra que la reforma al ISR arroja mejores resultados distributivos que la reforma del IVA, ya que los deciles altos son los que presentan mayor carga impositiva que se ve reflejada en un impacto positivo en todos los deciles de hogares, a pesar, de que los de mayor impacto positivo son los deciles más aportadores. Por lo tanto, estas reformas deberían ir acompañadas de una estructura impositiva más progresiva o un mejor mecanismo redistributivo. Sin embargo, transferencias dirigidas hacia la salud y educación equivaldrían a que un buen porcentaje de la población que se encuentra en pobreza tanto moderada como extrema podrían salir de ésta, incluso la brecha de la pobreza podría empezar a disminuir.

\section{Conclusiones.}

En esta investigación se realizó un análisis del impacto de diferentes escenarios alternativos sobre las principales variables de la economía, a través de simulaciones, representadas por la MCS, y a partir de sus resultados se analizó el cambio presentado en los índices de pobreza y la desigualdad 
a través del índice FGT y el coeficiente de Gini. Para estos análisis, se tomó como base de datos la MCS para México con año base 2008, llamada MCS-MX08, utilizando una metodología de equilibrio general lineal denominada multiplicadores lineales.

La primera parte de la investigación muestra los efectos económicos producto del impacto a la economía bajo los tres escenarios propuestos: i) el aumento del 2\% al IVA para ser transferido a los tres primeros deciles, ii) el impacto positivo a los sectores salud y educación en 1,41\% con respecto al PIB y, finalmente, iii) el aumento del 5\% al ISR igualmente para los tres primeros deciles.

Esta primera simulación ofrece dos resultados implícitos: por un lado, se hace referencia al ingreso a la economía de 11.599 millones de pesos mexicanos (610 millones de dólares americanos), que se traducen en un aumento en el output del sector de transportes, correos y almacenamiento y del sector generación, transmisión y distribución de energía eléctrica, es decir, la redistribución de la renta les impacta positivamente, en mayor proporción que a los demás sectores. Por otro lado, un aumento en los ingresos de los hogares más pobres impacta positivamente el output de los sectores de servicios de alojamiento temporal, servicio de esparcimiento cultural y deportivo y de servicios inmobiliarios, confirmando que un aumento en los ingresos de los hogares más pobres es destinado a actividades de ocio y recreación, sin mejorar sus áreas prioritarias como lo son la alimentación, la salud y la educación.

El escenario alternativo referente al aumento en un 2\% el IVA para transferirlos a los tres primeros deciles no trae grandes beneficios para la economía mexicana, ya que solo genera un aumento del $0,17 \%$ del agregado de la economía. Además, es posible que al aumentar el IVA que va dirigido a toda la población sin excluir clases sociales se vea afectada la capacidad de compra de los hogares pobres, causándole efectos negativos de manera individual, debido a las distorsiones presentadas en los precios relativos de los productos.

En el caso de la recaudación del 1,41\% en proporción del PIB por IEUE, para ser transferida a la salud y la educación, efectivamente la distribución del superávit de las transferencias a salud y educación beneficia a los hogares, pero en mayor medida la de los últimos deciles que corresponden a los de mayor ingreso. Con esto se demuestra que, aunado a este tipo de reformas, se debe presentar un mejor mecanismo redistributivo, con el fin de que se vean mayormente beneficiados los primeros deciles de la población. Por otro lado, se percibe el aumento de los sectores de servicios de alojamiento temporal, inmobiliarios y esparcimiento cultural al igual que resultados anteriores.

Por último, aumentar un 5\% el ISR para personas físicas para transferirlo a los tres primeros deciles refleja que, ante un mayor ingreso de los primeros deciles, la redistribución de la renta favorece las actividades recreativas dejando a un lado sectores prioritarios como la salud, educación y nutrición. A grandes rasgos, el sector terciario se beneficia en mayor proporción junto con los últimos deciles mostrando que los mayores aportadores son los que obtienen mejores beneficios.

$\mathrm{Al}$ analizar los diferentes panoramas alternativos desde su incidencia en la pobreza, se llega a que una buena combinación que arrojaría los mejores resultados resulta del aumento del 1,41\% con respecto al PIB a la salud y la educación junto con un aumento del 5\% del ISR para ser transferido a los tres primeros deciles de hogares mexicanos. La mayoría de los porcentajes de cambio no rebasan el 1\%, incidiendo principalmente en la pobreza moderada, y beneficiando a la población que se encuentra en los deciles más bajos.

Además, si se mejoran las condiciones en salud y educación, un porcentaje considerable de la población que se encuentra en pobreza tanto moderada como extrema podrían no padecerlas, y para aquellos que siguieran siendo pobres, lo serían con menor severidad. 
A pesar de que la reforma del ISR presenta mejores resultados que la reforma del IVA, ya que esta no introduce distorsiones en los precios relativos, resulta más difícil de implementar, debido a que la mayor carga impositiva la recibirían los deciles de mayor ingreso. Sin embargo, los efectos del impacto muestran que al mismo tiempo los deciles más altos se beneficiarían en mayor proporción que los deciles más bajos, viendo compensado el aumento de sus contribuciones. Por lo tanto, estas reformas deberían ir acompañadas de una estructura impositiva más progresiva o un mejor mecanismo redistributivo.

Si se lograra una mayor focalización de los hogares en condición de pobreza, estos ante un aumento de sus ingresos, empezarían a perder asistencia social, ya que los beneficios otorgados por el gobierno empezarían a disminuir a través de un aumento de los impuestos.

Huesca y Araar (2016) y Scott (2014) encontraron un aumento en el efecto del sistema fiscal de México en la reducción de la desigualdad entre el 2008 y 2010. Estos hallaron una progresividad creciente alimentada por TMC y una baja carga impositiva en los primeros deciles de ingreso. Por lo que el sistema fiscal mexicano se ha visto más progresivo. Sin embargo, la baja capacidad de redistribución a través de los beneficios como se mostró en esta investigación se debe a la escasa cobertura de los programas sociales, debido a la incapacidad del sistema tributario de recolectar impuestos en los deciles más altos de ingreso de los hogares mexicanos.

Como conclusión general, el programa social Oportunidades que continúa siendo una política importante para el gobierno federal, deberá ser combinada con alguna otra propuesta que ayude a lograr mejores resultados. Se recomienda mejorar la metodología de funcionamiento en cuanto a la focalización de los hogares pobres para aumentar el dinero que se les destina, y sobre todo invertir directamente en salud y educación. La implementación de alguna propuesta alternativa deberá ser financiada para mantener un presupuesto equilibrado, siendo alguna de estas las reformas presentadas anteriormente, teniendo en cuenta que cuanto más suba un impuesto más difícil será su implementación, debido a la posible resistencia de los deciles con mayor ingreso al ver aumentado sus pagos.

Por otro lado, se concluye que la financiación del combate a la pobreza a través del IVA refleja menor impacto que al financiarse con el ISR, debido al aumento de la distorsión tanto de precios como de salarios que afectan a la economía. Además, una buena propuesta radica en la inversión en salud y educación ya que potencializaría las capacidades de los individuos.

\section{Referencias.}

Aguayo, E., Chapa, N., \& Rangel, E., (2009). Análisis de la Generación y Distribución del Ingreso en México del Programa Oportunidades a través de un Modelo Lineal del Flujo Circular de la Renta. La Economía Mexicana en 19 Miradas, 469-499.

Aguilar, G. \& Lagunas, S. (2016) ¿Resultados positivos con la reforma fiscal de México en 2014? Punto de Vista, 7(11), 99-116.

Araar, A. (2008). Social classes, inequality and redistributive policies in Canada. CIRPÉE, working paper $\mathrm{N}^{\circ} 0817$, Université Laval.

Azevedo, J., Inchaust, G., \& Sanfelice, V. (2013). Decomposing the Recent Inequality Decline in Latin America. Policy Research Working Paper, The World Bank, № 6715.

Banco Mundial (2004). The Distribution of Benefits from Public Expenditure, Ch. 2, Mexico Public Expenditure Review. 
Beltrán, L., Cardenete, M., Delgado, M., \& Núñez G. (2016). Análisis estructural de la economía mexicana para el año 2008. Ensayos Revista de Economía, 35(1), 1-38.

Bird, R., \& Zolt E. (2014). Redistribution via Taxations: The Limited Role of the Personal Income Tax in Developing Countries. Annals of Economics and Finance, Society for AEF, 15(2), 625-683.

Britto, T. (2005). Recent Trends in the Development Agenda of Latin America: An Analysis of Conditional Cash Transfers. Manchester (Reino Unido): Institute for Development Policy and Management (IDPM).

Cámara, A. (2008). Estimación de la Matriz de Contabilidad Social de Madrid para el año 2000: Análisis del impacto de los fondos europeos 2000-2006 en la Región aplicando la metodología de Multiplicadores Lineales. Consejería de Economía y Hacienda, Comunidad de Madrid.

Campos-Vazquez, R., Esquivel, G., \& Lustig, N. (2014). The rise and fall of income inequality in Mexico: 1989-2010”. En: Falling Inequality in Latin America: Policy Changes and Lessons. Capítulo 7, WIDER Studies in Development Economics, Oxford University Press.

Campoy-Muñoz, P., Cardenete, M., \& Delgado, M. (2017). Assessing the economic impact of a cultural heritage site using social accounting matrices: The case of the Mosque-Cathedral of Cordoba. Tourism Economics, 23(4), 874-881.

Cardenete, M., \& Delgado, M. (2011). Análisis de la estructura de la economía georgiana. Papeles de Europa, 23, 21-42.

Cardenete, M., \& Delgado, M. (2013). Analisis de la Economia Andaluza con la Matriz de Contabilidad Social de Andalucia del año 2005, Cuadernos de Ciencias Economicas y Empresariales, 64, 11-32.

Cardenete, M., Delgado, M., \& Fuentes, P. (2013). Análisis del impacto de los Fondos Europeos en Andalucía: 2000-2006. Estudios de economía aplicada, 31(1), 1-26.

Casares, E., García, M. Ruiz, L., \& Sobarzo, H. (2015). “Distribución del Ingreso, Impuestos y Transferencias en México”. El Trimestre Económico, 82-3(327), 523-558.

Cecchini, S., \& Madariaga, A. (2011). Programas de Transferencias Condicionadas. Balance de la experiencia reciente en América Latina y el Caribe. Cuadernos de la Cepal, 95, 1-220.

Cecchini, S., \& Martínez, R. (2011). Protección social inclusiva en América Latina: una mirada integral, un enfoque de derechos. Libros de la CEPAL, 111, Santiago de Chile.

CEEY (2012). El México del 2012. Reformas a la Hacienda pública y al sistema de protección social. Centro de Estudios Espinosa Yglesias.

CEEY (2013). El México del 2013. Hacia una reforma integral de la Hacienda pública. Centro de Estudios Espinosa Yglesias. 
Domínguez, M. (2009). Aplicación de un modelo de multiplicadores contables y de análisis estructural a políticas sociales seleccionadas en el Estado de Nuevo León. Ensayos, 28(2), 95-137.

Dougherty, S., \& Escobar, O. (2013). The determinats of informality in Mexico's states. OECD Economics Department, Working papers N 1043 , OECD Publishing.

Duncan, R. (2010). Essays on personal income taxation and income inequality. Tesis de doctorado. Universidad de Georgia.

ENIGH (2012). Encuesta Nacional de Ingreso y Gasto de los Hogares, tradicional, tabulados básicos. México: INEGI.

Escobar-Latapí, A., González de la Rocha, M., \& Cortés, F. (2005). Evaluación cualitativa del Esquema Diferenciado de Apoyos 2005. CIESAS-Colegio de México: Guadalajara, Jalisco, México.

Foster, J., Greer, J., \& Thorbecke, J. (1984). A class of Decomposable Poverty Measures. Econometrica, 52 (3), 761-766.

Fuentes, H. (2012). Estudio de Evasión Fiscal Mediante el Uso de Efectivo. Ciudad de México: Centro de Estudios Estratéticos.

Gertler, P., Martínez, S., \& Rubio-Codina, M. (2012). Investing Cash Transfers to Raise LongTerm Living Standards. American Economic Journal: Applied Economics, American Economic Association, 4(1), 164-192.

González-Andrade, S., \& Fuentes Flores, N. (2010). Matrices de contabilidad social aplicadas a poblaciones rurales (MCSAP) para analizar el combate a la pobreza. Ra Ximhai, Revista de Sociedad, Cultura y Desarrollo Sustentable, 6(2), 259-274.

Goñi, E., López, J., \& Servin, L. (2008). Fiscal Redistribution and Income Inequality in Latin America, World Bank Policy Research, Working Papers Series, № 4487 2, Washington D.C.

Holzmann, R., \& Jorgensen, O. (2000). Manejo social del riesgo: un nuevo marco conceptual para la protección social y más allá. documento de trabajo, № 0006, Washington, D.C., Banco Mundial.

Huesca, L., \& Araar, A. (2016). Comparison of Fiscal System Progressivity Over Time: Theory and Application in Mexico. Estudios Económicos, 31(1), 3-45.

INEGI (2013). Matriz Insumo-Producto 2008. México: Sistema de Cuentas Nacionales de México.

Jiménez, M. (2009). Iniciativa de Ley de la contribución para el combate a la pobreza, remitida por el ejecutivo federal. Ciudad de México: Senado de la República.

KPMG (2013). Reforma Fiscal 2014. Ciudad de México. 
Kumler, T., Verhoogen, E., \& Frias, J. (2013). Enlisting employees in improving payroll-tax compliance: Evidence from Mexico. IZA, Discussion papers $\mathrm{N}^{\circ} 7591$, Institute for the Study of Labor.

Leontief, W. (1941). The Structure of American Economy, 1919-1929: an Empirical Application of Equilibrium Analysis. Cambridge: Harvard University Press.

Lima, M., Cardenete, M., Hewings, G., \& Vallés, J. (2005). A Structural Analysis of a Regional Economy using a Social Accounting Matrices: 1990-1999. Investigaciones Regionales, 5, 113-138.

López-Acevedo G., \& Salinas, A. (2000). The Distribution of Mexico's Public Spending on Education, World Bank Policy Research, Working Paper No. 2404.

Lustig, N.,Pessino, C., \& Scott, J. (2014). The impact of taxes and social spending on inequality and poverty in Argentina, Bolivia, Brazil, Mexico, Peru, and Uruguay: Introduction to the special issue, Public Finance Review, 42(3), 287-303.

Medina, F. (2001). Consideraciones sobre el índice de Gini para medir la concentración del ingreso. Estudios Estadísticos y Prospectivos, CEPAL, 9, 1-43.

Minzer, R., Pérez, A., \& Solís, V. (2014). Análisis de algunas medidas fiscales en México y sus implicaciones bajo un enfoque de equilibrio general computable. Serie Estudios y Perspectivas, CEPAL, 152, 1-59.

Núñez, G. (2003). Un análisis Estructural y de Equilibrio General de la Economía Mexicana. Tesis de Doctorado. Universidad Autónoma de Barcelona, España.

Parra, J., \& Wodon, Q. (2009). SimSIP SAM: A Tool for the Analysis of Input-Output Tables and Social Accounting Matrices, The World Bank.

Programa de las Naciones Unidas para el Desarrollo (2011). Informe sobre Desarrollo Humano. México 2011. México: PNUD.

Prospera (2015). Reglas de operación 2015. Disponible en: www.prospera.gob.mx/swb/es/PROSPERA2015/Quees_PROSPERA

Pyatt, G., \& Round, J. (1979). Accounting and Fixed Price Multipliers in a Social Accounting Matrix Framework. The Economic Journal, 89(356), 850-873.

Rodríguez, L., \& Morales, J. (2014). Impacto del Programa Oportunidades en una economía rural a partir de modelos multisectoriales. Realidad, Datos y Espacio. Revista Internacional de Estadística y Geografía, 5(1), 32-51.

Sadoulet, E., Janvry, A., \& Davis, B. (2001). Cash Transfer Programs with Income Multipliers: Procampo in Mexico. International Food Policy Research Institute IFPRI. Discussion paper $\mathrm{N}^{\circ} 99$.

Scott, J. (2014). Redistributive impact and efficiency of Mexico's fiscal system, Public Finance Review, 42, 368-390.

Sen, A. (2000). Desarrollo y libertad. Madrid: Editorial Planeta. 
SHCP (2008). Distribución del pago de impuestos y recepción del gasto público por deciles de hogares y personas. Ciudad de México: SHCP.

SHCP (2012). Distribución del pago de impuestos y recepción del gasto público por deciles de hogares y personas. Resultados para el año de 2012. Ciudad de México: INEGI.

Skoufias, E., \& Parker, S. (2001). Conditional Cash Transfers and Their Impacts on Child Work and Schooling: Evidence from the Progresa Program in Mexico, International Food Policy Research Institute (IFPRI), FCND Discussion Paper, Nº 123, Washington, D.C.

Sobarzo, H. (2007). La reforma fiscal en México. Comercio Exterior, 57(10), 832-840.

Stone, R. (1978). The Disaggregation of the Household Sector in the National Accounts. World Bank Conference on Social Accounting Methods in Development Planning. Washington: The World Bank.

Tello, C., \& Hernández, D. (2010). Sobre la reforma tributaria en México. Economía UNAM, 7(21), 37-56.

Villatoro, P. (2005). Programa de transferencias monetarias condicionadas: experiencias en América Latina, Revista de la Cepal, 86, 87-101.

Yaschine, I., \& Dávila L. (2008). Why, when and how should beneficiaries leave a CCT programme? En: Poverty in Focus, $\mathrm{N}^{\circ}$. 15, agosto 2008. Brasilia. International Poverty Centre, 8-9.

Yúnez, A., \& González, S. (2008). Efectos multiplicadores de las actividades productivas en el ingreso y pobreza rural en México. El Trimestre Económico, 75(2), 349-377. 